\title{
Impact of ethnicity and season on body composition: results from the Vitamin D, Food Intake, Nutrition and Exposure to Sunlight in Southern England (D-FINES) Study
}

\author{
Barbara Engel $^{1}$, P. Lee ${ }^{1}$, L. Bottle $^{1}$, P. Cardew ${ }^{2}$ and S. A. Lanham-New ${ }^{1}$ \\ ${ }^{1}$ University of Surrey, Guildford, UK and ${ }^{2}$ Guildford Nuffield Hospital, Guildford, UK
}

The principal objectives of the D-FINES study are to compare vitamin D status, food intake, bone health indices and sunlight exposure in Caucasian and Asian women living in Southern England. It is known that in women both muscle and fat mass influence whole-body $\mathrm{BMD}^{(1)}$ and the aim of the present subsidiary study was to examine for differences in body composition and compare the relationship between body composition components in Asian and Caucasian women.

Measurements of body composition were undertaken in seventy-two Asian and 227 Caucasian women in autumn-winter (A/W) with a follow-up assessment in spring-summer (S/S) by dual X-ray absorptiometry (QDR-4500; Hologic Inc., Bedford, MA, USA). Measures of whole-body bone mineral density (BMD), whole-body bone mineral content (BMC), fat mass and lean mass were undertaken. Regional as well as total measurements were available.

\begin{tabular}{|c|c|c|c|c|c|c|c|c|}
\hline & \multicolumn{3}{|c|}{ Caucasians } & \multicolumn{2}{|c|}{ Asians } & \multirow{2}{*}{\multicolumn{3}{|c|}{$\begin{array}{l}\text { Significance of difference } \\
\text { between groups: } P\end{array}$}} \\
\hline & Mear & \multicolumn{2}{|c|}{ SD } & Mean & SD & & & \\
\hline Age (years) & 51.2 & \multicolumn{2}{|c|}{13.7} & 50.5 & \multicolumn{2}{|l|}{1.1} & \multicolumn{2}{|c|}{0.3} \\
\hline Weight (kg) & 69.0 & \multicolumn{2}{|c|}{12.3} & 68.0 & \multicolumn{2}{|l|}{14.1} & \multicolumn{2}{|c|}{0.5} \\
\hline Height (m) & 1.63 & \multicolumn{2}{|c|}{0.06} & 1.56 & 0.05 & & \multicolumn{2}{|c|}{$<0.0001$} \\
\hline BMI $\left(\mathrm{kg} / \mathrm{m}^{2}\right)$ & 26.0 & \multicolumn{2}{|c|}{4.79} & 27.9 & 5.95 & & \multicolumn{2}{|c|}{0.01} \\
\hline & \multicolumn{4}{|c|}{ Caucasians } & \multicolumn{4}{|c|}{ Asian } \\
\hline & \multicolumn{2}{|c|}{$\mathrm{A} / \mathrm{W}$} & \multicolumn{2}{|c|}{$\mathrm{S} / \mathrm{S}$} & \multicolumn{2}{|c|}{$\mathrm{A} / \mathrm{W}$} & \multicolumn{2}{|c|}{$\mathrm{S} / \mathrm{S}$} \\
\hline & $\overline{\text { Mean }}$ & SD & Mean & SD & Mean & SD & Mean & $\overline{\mathrm{SD}}$ \\
\hline $\begin{array}{l}\text { Whole-body } \\
\text { BMD }\left(\mathrm{g} / \mathrm{cm}^{3}\right)\end{array}$ & 1.13 & 0.10 & $1.12 * * *$ & 0.10 & $1.10 \dagger$ & 0.09 & $1.09 *$ & 0.10 \\
\hline $\begin{array}{l}\text { Whole-body } \\
\text { BMC (kg) }\end{array}$ & 2.20 & 0.31 & $2.19 * *$ & 0.31 & $2.01 \dagger+\dagger$ & 0.26 & 2.00 & 0.28 \\
\hline Total fat $(\mathrm{kg})$ & 24.5 & 8.23 & $24.9 *$ & 8.34 & 26.5 & 8.91 & 27.4 & 9.48 \\
\hline Total lean (kg) & 40.8 & 4.83 & 41.0 & 5.50 & $37.8+\dagger$ & 5.26 & 38.5 & 5.14 \\
\hline
\end{tabular}

As shown in the Table, the age and weight of the two groups of women were not significantly different $(P>0.05)$. However, height was lower and BMI significantly higher in the Asian cohort. Whole-body BMD, whole-body BMC, lean mass and fat mass were significantly different between the two groups; fat mass was greater in Asian women, whereas the other three variables were lower. The difference in fat mass was not retained when adjusting for age. The difference in BMC remained even when measurements were standardised for height (and age).

Whole-body BMD and whole-body BMC decreased over winter in Caucasian women, whereas fat mass increased. Lean mass remained stable. In Asian women only whole-body BMD showed a significant decrease. BMD and BMC were positively correlated with total lean tissue in Asian $(R 0.3 ; P=0.01$ and $R 0.5 ; P=0.0001$ respectively) and Caucasian women $(R 0.4$ and $R 0.6 ; P=0.0001)$. In Asian women a greater baseline fat mass correlated with a positive change in whole-body BMD over winter $(R 0.03 ; P=0.035)$. This relationship was not seen in Caucasian women.

Body size is known to account for much of the difference in bone density between Asian and Caucasian women; however, in the present study the differences were maintained when standardising for height and also age. A meta-analysis of exercise programmes has indicated that exercisers can gain $1 \%$ BMD over 1 year ${ }^{(2)}$. Thus, losses of a similar magnitude in just a few months perhaps put the changes measured in the current study into context. The potential protective effect of fat mass against bone loss in Asian women will be investigated further by examining the regional body composition differences between these two cohorts.

This work was funded by the Food Standard Agency (N05064). The views expressed are the authors' own.

1. Visser M, Kiel DP, Langlois J, Hannan MT, Felson DT, Wilson PW \& Harris TB (1998) Appl Radiat Isot 49, 745-747.

2. Wallace BA \& Cumming RG (2000) Calcif. Tissue Int 67, 10-18. 